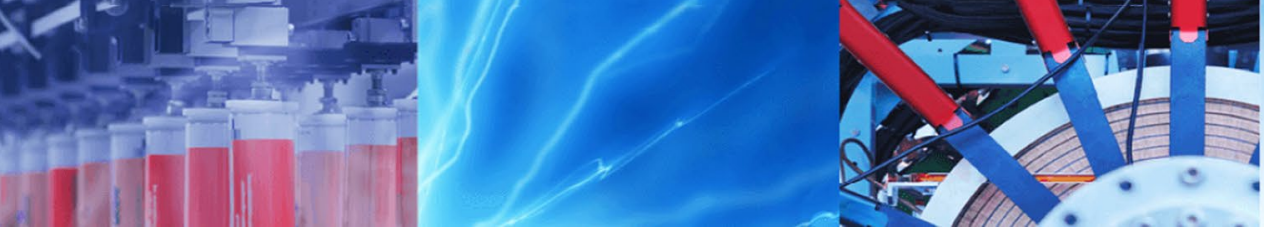

Research Article

\title{
Petroleum production impacts on the economic growth of the OPEC countries: panel ARDL approach
}

\author{
Saeid Satari Yuzbashkandi ${ }^{1}$ Mehrdad Aghaei Sadi ${ }^{2}$
}

Received: 12 January 2020 / Accepted: 11 March 2020 / Published online: 18 March 2020

(c) Springer Nature Switzerland AG 2020

\begin{abstract}
The object of this study is to examine the relation between economic growth, in terms of gross domestic production (GDP) and petroleum production (PP) for the Organization of Petroleum Exporting Countries over the period of 2000-2016. The panel co-integration tests were applied to appraise the being of the relationship while the dynamic OLS (DOLS) and fully modified OLS (FMOLS) panel co-integration methods were applied to explore the long-run effect of PP on the GDP growth. Moreover, to estimate the short-run coefficient and causality relationship, the pool mean group (PMG) method was employed. The findings indicated that the GDP and PP are non-stationary and co-integrated series. The estimated panel coefficients using FMOLS, DOLS and PMG were calculated to be $0.64,0.76$ and 0.86 , respectively. In addition, there was a unilateral causality from PP to GDP.
\end{abstract}

Keywords Economic growth · OPEC countries · Petroleum production · Panel causality · Panel co-integration

\section{Introduction}

Energy as a driving force of development plays a significant role in the country's economic growth [1]. A key notion in the economics of production procedure is the reproducibility. Some inputs that engaged in the production procedures are non-reproducible such as energy, while other production factors such as capital, labor and natural resources in the long-run are reproducible [2]. Petroleum components (crude oil, natural gas pipeline, refined petroleum products and, other liquids) although being one of the most valuable and scarce natural endowments, are used both the final consumption product and an energy input [3].

The Organization of the Petroleum Exporting Countries (OPEC) is a permanent and intergovernmental cartel that was established in September 1960 in Baghdad, Iraq by the first five members i.e. Saudi Arabia, Iran, Iraq, Kuwait, and Venezuela. Members admitted afterward include Qatar, Indonesia, Libya, Algeria, Nigeria, Ecuador, Gabon, Angola, the United Arab Emirates, and Equatorial Guinea then joined the OPEC [4]. In this case, this cartel now comprises of 12 members. The mission of OPEC can be divided into unifying the petroleum policies of its Member, and to provide member states with economic and technical aid. This cartel manages the supply of petroleum to determine the price on the market to avoid price fluctuations.

In this survey, we conducted our analysis with 11 OPEC members include Iran, Iraq, Kuwait, Saudi Arabia, Venezuela, Qatar, Libya, the United Arab Emirates, Algeria, Nigeria, Ecuador, and Angola. The OPEC countries were selected as they have enough natural petroleum resources (crude oil, NGPL and other liquids) and petroleum plays a key role in the economy of these countries [5].

The OPEC organization is known for its vast and wide crude oil, NGPL (natural gas pipeline) endowments

\footnotetext{
$\triangle$ Saeid Satari Yuzbashkandi, satari.saeed@yahoo.com; Mehrdad Aghaei Sadi, m.aghaei90@yahoo.com | ${ }^{1}$ Agricultural Economics Department, Faculty of Agriculture, Tarbiat Modares University (T.M.U.), P.O. Box: 14115-336, Tehran, Iran. ${ }^{2}$ Biosystems Engineering Department, Faculty of Agriculture, Tarbiat Modares University (T.M.U.), P.O. Box: 14115-336, Tehran, Iran.
} 
potential and its vital share in the global supply of energy. In 2016, the OPEC countries were accounted for around $41.1 \%$ of the total world petroleum production and $73.4 \%$ of the proven world reserves [4]. Figure 1 shows the daily petroleum production of OPEC and the world in 2000-2016. It can be seen that over this period the OPEC produced more than $41 \%$ of world petroleum [6].

Since the OPEC countries are rich in energy resources, large oil reservoirs, giant underground mines, one of the examples of growth patterns is the pressure on natural resources. Therefore, planning for production and consumption of energy is important and must be accomplished with great consideration. The economy of OPEC countries heavily relies on oil. Figure 2 depicts oil rent (oil revenue minus production cost) as a share of GDP with the respect to the world's average $7.11 \%$ in 2014. Kuwait has the world's first position with $53.04 \%$ of GDP dependence on oil revenue followed by Iraq and Saudi Arabia [7].

Since the availability of the production factors is effective for the firm's economic level production, the allocation of any production factor leads to different levels of goods and services. The production of firms determines the total production and, ultimately, the level of economic growth. Therefore, production factors affect economic growth by changing the level of firms output. If we consider the production of each firm as a function of the utilization of various factors,

$Q=f\left(x_{i}\right)$

where $Q$ is output and $x$ is the different production factors. It is supposed that there is a straight relation between the use of these production factors and the production level when increasing each of these inputs will increase production. One of these factors considered as a production factor is energy in its various forms.

Natural resources and endowments are the important sources of the national properties over the globe [1]. In modern economic growth theories which started to be developed in the 1950s and 1960s, natural resources were absent. In these growth models, capital and labor are the only most substantial factors that affects economic growth
Fig. 1 Comparison of the World and the OPEC countries petroleum production in the period of 2000-2016 [6]
Fig. 2 Amount of oil rent, percent of GDP [7]
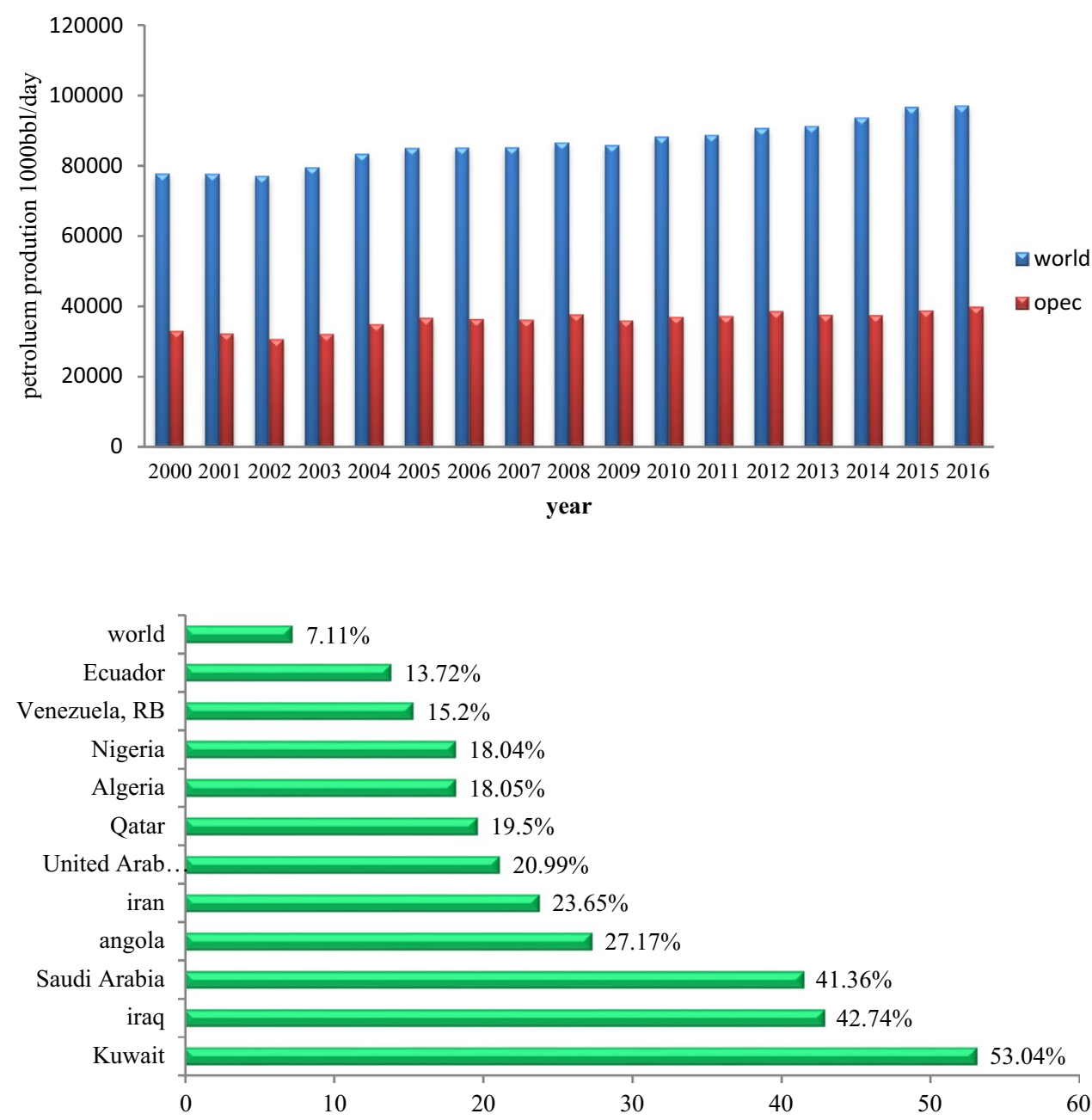
[8]. Models have developed by resource economists that consider the role of natural resources including energy in the process of growth [9]. Stern [2] studied the factors which can affect the relationship between energy utilization and economic activities and defined the general state of a production function as,

$\left(Q_{1}, \ldots, Q_{m}\right)=f\left(A, X_{1}, \ldots, X_{n}, E_{1}, \ldots, E_{p}\right)$

where $Q_{i}, X_{i}, E_{i}$ and $A$ represent the various economic goods and services, production factor such as capital and labor, energy inputs (e.g. petroleum) and productivity index, respectively. In this function, the relationship between the energy and total production is affected by factors such as the substitution of the energy with the other factors, technological changes, changes in the composition of the energy factor, the composition of the product and composition of the factors. Thus, if the production is considered only as a function of labor, capital and, various energy forms, it can be written as,

$Q=A F(L, K, E)$

$\frac{\partial Q}{\partial K}>0, \quad \frac{\partial Q}{\partial L}>0, \quad \frac{\partial Q}{Q E}>0$

There is a direct relation between the usage of these inputs and the level of production when increasing each of these inputs increases production. In other words, when a country increases the production, there would be an increasing pressure on the resources causing an increment in demand for various forms of energy. Hence, the association between economic growth and petroleum production has attracted the significant attention of many economic analysts.

\section{Literature review}

Various studies have examined the role of natural resources and energy in economic growth. Some of these studies have deduced that natural resources do not lead to growth. For example [10] compared the relationship between natural resources and gradual reform in both resource-abundant and resource-trivial countries. He pointed out that the abundance of natural resources determined the growth and reform strategy. Also, they addressed that poor economic and political conditions caused the disappointing performance of rich-resource countries. The results of this study are in line with the results of previous studies carried out by $[11,12]$.

Sachs and Warner [13] evaluated the relationship between natural resource abundance and economic growth. They found that countries with rich natural endowments have a tendency to grow slowly than poor natural resource economies. In addition, they explored this negative relationship by studying the cross-country effects of resource endowments on trade policy, bureaucratic efficiency, and other determinants of growth.

Ahrend [14] investigated the reasons behind largely differing regional growth performance in 77 Russian regions. He showed that differences in institutional characteristics or economic reform explain a relatively small part of the observed difference in regional growth performance. In contrast, a region's natural and human resource endowments and also its initial industrial structure had a large influence on its economic growth.

Barbier [15] investigated the effect of the natural endowment on economic growth among transition countries. This study rejected the results of a seminal study conducted by Sachs and Warner, which considered natural resources as a disadvantage and curse. In fact, resource abundance has a positive effect on economic growth. Bildirici and Kayıkçı [16] studied the effects of oil production on the economic growth in major oil exporting Eurasian countries using the Panel ARDL approach for the period of 1993-2010. Results indicated that oil production and economic growth were co-integrated for these countries, and also there was a positive bi-directional causality between these variables both in the short and long run.

Reynolds and Kolodziej [17] assessed the transition of the Former Soviets Union and oil production decline. The econometric analysis revealed that for Soviet and former Soviet in the 1980s and 1990s fall in GDP did not Granger causality the decline in oil production, but Grange causality from a decline in oil production to fall in GDP was true.

Bashiri Behmiri and Pires Manso [18] surveyed the Granger causality among crude oil consumption and economic growth in twenty-seven OECD countries for the period of 1976-2009 using a panel multivariate approach, and their findings showed a bilateral causality linkage between crude oil consumption and GDP.

Behmiri and Pires Manso [19] studied the co-integration and the Granger causality relationships between crude oil consumption and economic growth in Latin America during 1980-2012. They used a multivariate panel framework model by including crude oil price as a control variable. Results with respect to long-run causality showed that in the Caribbean and South America, economic growth and oil consumption does not Granger cause each other. However, in Central America, there is a unidirectional causality relationship between crude oil consumption to economic growth.

Using the ARDL testing approach, Bildirici and Bakirtas [3] investigated the causality relation between economic growth and coal, natural gas and oil consumption in BRICTS countries over the period of 1980-2011. They found that there is a bilateral causality between oil energy 
consumption, natural gas energy, and economic growth. Solarin and Ozturk [5] surveyed the linkage between natural gas consumption and economic growths using the panel Granger causality test in 12 OPEC member countries for the period of 1980-2012. Their findings showed the existence of feedback relation between natural gas consumption and economic growth in OPEC members.

Given the importance of petroleum in the economy of the OPEC countries, since the study of the role of petroleum in these countries has not been studied so far, in this study, we assessed separated and in more detail the impacts of the petroleum production on economic growth in OPEC countries by using the Panel RADL approach over 2000-2016.

\section{Material and methods}

\subsection{Model and data}

In this study, the relationship between petroleum production (PP) and the economic growth (GDP) for the OPEC countries have been investigated over the period of 2000-2016. It has been assumed that economic growth is a function of petroleum production, so the long-run equation in double-natural logarithm form can be as follows,

$\ln G D P_{i t}=f\left(\ln P P_{i t}\right)$

where GDP indicates the real gross domestic product per capita which has been measured in US\$ at 2010 prices for each country. The PP is the petroleum production in 1000 barrels/per day. The petroleum production includes the production of crude oil, natural gas pipeline, and other liquids. The PP data were collected from the U.S. Energy Information Administration (EIA) and the OPEC Annual Statistical Bulletin 2017 while the real GDP data were collected from the World Development Indicators [7].

\subsection{Methodology}

\subsubsection{Cross-sectional dependence test}

An important issue in panel data studies is the crosssectional dependency among the entities of the panel. There exist correlations among different groups (crosssection) in the panel. In the existing case of cross-sectional dependence, the Seemingly Unrelated Regressions (SUR) estimator is more efficient than the pooled Ordinary Least squares (pooled OLS). Thus, it is crucial to test the crosssectional dependence before modeling and estimating panel data to avoid the misspecification of the model which results in invalid tests, bias, inconsistency, and inefficiency in parameter estimates. Breusch and Pagan LM test has been widely used to examine the cross-sectional dependency. The standard panel data model is as follow,

$G D P_{i t}=\alpha_{i}+\beta^{\prime} P P_{i t}+u_{i t}, \quad i=1, \ldots, N$ and $t=1, \ldots, T$

where $\mathrm{i}$ and $\mathrm{t}$ are the cross-section and time dimensions, respectively while $\alpha_{\mathrm{i}}$ and $\beta$ also indicate the individual intercepts and slope coefficients, respectively.

Breusch and Pagan [20] proposed a Lagrange Multiplier (LM) Statistic, which is valid when the T value is high. This statistic is distributed as chi-squared with $\mathrm{N}(\mathrm{N}-1) / 2$ degrees of freedom under the null hypothesis of interest and given by,

$L M=T \sum_{i=1}^{N-1} \sum_{j=i+1}^{N} \hat{\rho}_{i j}^{2}$

where $\hat{\rho}_{\mathrm{ij}}^{2}$ is the sample estimate of the pair-wise correlation of the residuals as follow,

$\hat{\rho}_{\mathrm{ij}}=\hat{\rho}_{\mathrm{ji}}=\frac{\sum_{\mathrm{t}=1}^{\top} \hat{\mathrm{u}}_{\mathrm{it}} \hat{\mathrm{u}}_{\mathrm{jt}}}{\left(\sum_{\mathrm{t}=1}^{\top} \hat{\mathrm{u}}_{\mathrm{it}}^{2}\right)^{1 / 2}\left(\sum_{\mathrm{t}=1}^{\top} \hat{\mathrm{u}}_{\mathrm{jt}}^{2}\right)^{1 / 2}}$

The scaled variant of LM test can be calculated as follow [21],

$\operatorname{CDLM}=\left(\frac{1}{N(N-1)}\right)^{\frac{1}{2}} \sum_{i=1}^{N-1} \sum_{k=i+1}^{N}\left(T \hat{\rho}_{i k}^{2}-1\right)$

However, when $\mathrm{N}$ is large and $\mathrm{T}$ is small, Cross-Sectional Dependency Lagrange Multiplier (CDLM) test likely show substantial size distortion. Pesaran [21] proposed a more general test that is reliable for both large and small panels as follow,

$C D=\sqrt{\frac{2 T}{N(N-1)}}\left(\sum_{i=1}^{N-1} \sum_{j=i+1}^{N} \hat{\rho}_{i j}\right)$

Following the null hypothesis of no cross-sectional dependence, $C D$ test is asymptotically distributed as normal and efficient even in small size panel.

\subsubsection{Panel unit root test}

In this section, the stationary or non-stationary nature of the given data has been investigated. This is because the pooled time series data which are similar to the time series data tend to show a time trend and they may be non-stationary [22]. The direct application of OLS or GLS to non-stationary data produces spurious results in regressions [23]. The existence of cross-sectional dependence 
in the series is detected by unit root tests that consider cross-sectional dependence such as Levin, Lin and Chu, Breitung, Hadri, and Im, Pesaran and Shin. Furthermore, these tests are more potent unlike the individual series unit test as they consider the information in cross-section data. Pesaran [24] created a panel unit root test allowing cross-section dependence and heterogeneity. He mentioned that if $y_{i t}$ is the observation on ith cross-section at time $t$, the variable can be determined based on the simple dynamic linear heterogeneous panel data model as,

$y_{i t}=\left(1-\emptyset_{i}\right) \mu_{i}+\emptyset_{i} y_{i, t-1}+u_{i t}, \quad i=1, \ldots, N ; \quad t=1, \ldots, T$

Considering the error term, $u_{i t}$ which has the singlefactor structure, $f_{t}$ is the unobserved common effectand $\varepsilon_{i t}$ is the individual-specific error as follow,

$u_{i t}=\gamma_{i} f_{t}+\varepsilon_{i t}$

Pesaran donates that Eq. 10 can be converted into the following expression as,

$\Delta \mathrm{y}_{\mathrm{it}}=\alpha_{\mathrm{i}}+\beta_{\mathrm{i}} \mathrm{y}_{\mathrm{i}, \mathrm{t}-1}+\gamma_{\mathrm{i}} \mathrm{f}_{\mathrm{t}}+\varepsilon_{\mathrm{it}}$

where $_{i}=\left(1-\emptyset_{i}\right) \mu_{i}, \beta_{i}=-\left(1-\emptyset_{i}\right)$ and $\Delta y_{i t}=y_{i t}-y_{i, t-1}$. The unit root hypothesis of interest, $\emptyset_{i}=1$, can now be written as,

$H_{0}: \beta_{i}=0$ for all $i$

$H_{1}: \beta_{i}<0, \quad i=1,2, \ldots, N_{1}, \quad \beta_{i}=0, \quad i=N_{1}+1, N_{1}+2, \ldots, N$

Following the Pesaran, the common factor $f_{t}$ can be proxied by cross-section mean of $y_{i t}$, namely $\bar{y}_{t=} N^{-1} \sum_{j=1}^{N} y_{j t}$, and its lagged value(s), $\bar{y}_{t-1}, \bar{y}_{t-2}, \ldots$ for $\mathrm{N}$ is sufficiently large. Our Pesaran-based test of the unit root hypothesis, on t-ratio of the ordinary least squares (OLS) estimate of $b_{i}\left(\hat{b}_{i}\right)$ in the following cross-section augmented Dickey-Fuller (CADF) regression:

$\Delta y_{i t}=\alpha_{i}+b_{i} y_{i, t-1}+c_{i} \bar{y}_{t-1}+d_{i} \Delta \bar{y}_{t} e_{i t}$

And the t-ratio can be calculated as:

$t_{i}(N, T)=\frac{\Delta \hat{y}_{i} \bar{M}_{w} y_{i,-1}}{\hat{\sigma}_{i}\left(\hat{y}_{i,-1} \bar{M}_{w} y_{i,-1}\right)^{1 / 2}}$

Pesaran also produced cross-sectionally augmented IPS (CIPS) statistics through the average of individual CADF test statistics that can be used for the entire of panel as follow;

$\operatorname{CIPS}(N, T)=t-b a r=N^{-1} \sum_{i=1}^{N} t_{i}(N, T)$ where $t_{i}(N, T)$ indicates the CADF statistics for ith crosssection unit.

\subsubsection{Panel cointegration test}

In this section, we proceeded to panel co-integration tests after the specification of the order of integration for the series to test the relation between economic growth and petroleum production in OPEC countries. In this study, Kao [25] and Pedroni [26] various co-integration methods were used to test the existence of the co-integration relationship. These two methods are both based on Engle and Granger residual based co-integration tests. One of the popular and most famous methods of panel co-integration is the Pedroni test. This method considers the heterogeneity among the individual entity of the panel. Although the Pedroni test considers vary individual effects in crosssectional dependencies, it is very similar to the Im et al. [27] tests [28]. The applied empirical model of panel cointegration is as follows,

$G D P_{i t}=\alpha_{i}+\delta_{t}+\beta_{i} P P_{i t}+\varepsilon_{i t}$

where $i=1,2, \ldots, N$ for each country, $t=1, \ldots, T$ for each country, $\alpha_{i}$ and $\delta_{t}$ represent the fixed effects of the section (country) and time, respectively. $\varepsilon_{i t}$ Isthe estimated residuals and indicative from the long-run relationship. Finally, the structure of these residuals is:

$\widehat{\varepsilon}_{i t}=\hat{\rho}_{i} \hat{\varepsilon}_{i t-1}+\widehat{u}_{i t}$

Pedroni [29] introduced two types of co-integration tests i.e. panel tests and group tests. The panel tests which are based on the within dimension method include four statistics namely panel rho-statistic, panel v-statistic, panel Philips-Perron (PP) statistic and panel ADF-statistic. Moreover, there are three statistic group tests that are based on between dimensions consist of group rho-statistic, group PP-statistic, and group ADF-statistic. For both of these, the null hypothesis is the absence of co-integration. The difference between these two types of tests is in the design of an alternative hypothesis. The only constraint of the Padroni co-integration test is that it is based on the common factor restriction hypothesis and does not compute the probable cross-sectional dependence [30]. The existence of this limitation can reduce the robustness and sustainability of residual based co-integration tests. In addition to the Pedroni Co-integration test, Kao's cointegration test was thus used to estimate the long-run relationship between Petroleum production and economic growth in the OPEC countries. Kao's test is based on the Engle-Granger two-step procedure method, which takes into account the homogeneity of panel components in the co-integration test. The null hypothesis of this test is 
the absence of co-integration relationship examined using the ADF test [28].

\subsubsection{Long-run relationships estimators}

Assuming co-integration among the studied variables, we can examine the long-run relationships among them. where $\mathrm{GDP}_{\mathrm{i}, \mathrm{t}}$ and $\mathrm{PP}_{\mathrm{i}, \mathrm{t}}$ are integrated with $\beta_{\mathrm{i}}$ slope coefficient, and $\beta_{i}$ may be Homogeneous or heterogeneous between the different sections (countries). This equation can be rewritten as follows:

$G D P_{i, t}=a_{i}+\beta_{i} P P_{i, t}+\sum_{j=-K_{i}}^{K_{i}} \gamma_{i, k} \Delta P P_{i, t-k}+v_{i t} \quad \forall t=1, \ldots, T$ and $i=1, \ldots, N$

Pedroni and Kau's methods have some limitations to estimating long-run or short-run coefficients in panel error correction models. Various modern econometric techniques have been proposed to investigate the existence of long-run co-integration vectors among variables such as ordinary least squares (OLS), fully modified ordinary least squares (FMOLS), dynamic ordinary least squares (DOLS), mean group (MG) and pooled mean group (PMG).

The FMOLS method generates reliable estimates for small samples. This approach is firstly introduced and developed by Peter and Hansen [31]. The advantage of FMOLS to EG techniques is introducing appropriate correction to overcome the inference problem in EG method and therefore the $t$ test for long -run estimates are valid [18].

The FMOLS is a non-parametric method quantifying the possible correlation between the components of model error terms and the first order differential of the explanatory variables with a constant coefficient to correct the serial correlation and finally modify the OLS estimator. Panel DOLS is fully a parametric co-integration technique that offers a computationally convenient alternative to the panel FMOLS estimator. Kao and Chiang [32] discussed the panel DOLS properties when there are fixed effects in the co-integration regression [33]. These two methods are efficient and consistent estimators to investigate long-term relationships and examine both serial and the potential intrinsic correlation between variables.

In the pooled panel models, the use of OLS methods to estimate the long-run relationship may lead to biased and unreliable results. Kao and Chiang [32] also showed that DOLS and FMOLS estimators have small sample biased, and both estimators provide almost identical results. In this study, the estimators of DOLS and FMOLS were used to estimate long-run relationship among variables.

3.2.4.1 FMOLS and DOLS estimators The FMOLS estimator has been developed by Pedroni [29]:

$G D P_{i, t}=a_{i}+\beta_{i} P P_{i, t}+\varepsilon_{i t} \quad \forall t=1, \ldots, T$ and $i=1, \ldots, N$ where $\gamma_{i, k}$, is the coefficient of first order differential explanatory variables.

If $\xi_{i, t}=\left(\widehat{\varepsilon}_{i, t}, \Delta P P_{i, t}\right)$ so we have:

$\Omega_{i, t}=\operatorname{Lim} E\left[\frac{1}{T}\left(\sum_{i=1}^{T} \xi_{i, t}\right)\left(\sum_{i=1}^{T} \xi_{i, t}\right)\right]$

That is equal to the long-run covariance of the process, which can be decomposed as $\Omega_{i}=\Omega_{i}^{0}+\Gamma_{i}+\Gamma_{i}^{\prime}$. In this equation, $\Omega_{i}^{0}$ indicates the covariance, and $\Gamma_{i}$ is equal to weighed the sum of auto-covariance. Finally, estimated the coefficient of FMOLS estimator can be calculated by:

$$
\begin{aligned}
\beta_{F M O L S}^{\star}= & \frac{1}{N} \sum_{i=1}^{N}\left[\left(\sum_{t=1}^{T}\left(P P_{i, t}-\overline{P P}_{i}\right)^{2}\right)^{-1}\right. \\
& \left.\times\left(\sum_{t=1}^{T}\left(P P_{i, t}-\overline{P P}_{i}\right)^{2} G D P_{i, t}^{*}-T \hat{\gamma}_{i}\right)\right]
\end{aligned}
$$

where $G D P_{i, t}^{*}=G D P_{i, t}-\overline{G D P}_{i}-\frac{\hat{\Omega}_{2, i, i}}{\hat{\Omega}_{2,2, i}} \Delta X_{i, t}$ and $\hat{\gamma}_{i}=\hat{\Gamma}_{2,1, i}$ $+\widehat{\Omega}_{2,1, i}^{0}-\frac{\widehat{\boldsymbol{\Omega}}_{2,1, i}}{\widehat{\boldsymbol{\Omega}}_{2,2, i}}\left(\widehat{\Gamma}_{2,2, i}+\widehat{\Omega}_{2,2, i}^{0}\right)$

To obtain an unbiased estimator of long-run parameters and an endogeneity correction of the variables used in the model, the DOLS estimator exerts the parameter adjustment of model errors by inserting past and future values of the first-order difference of explanatory variables. The estimated coefficient of DOLS estimator express is:

$\beta_{D O L S}^{\star}=\frac{1}{N} \sum_{i=1}^{N}\left[\left(\sum_{t=1}^{T}\left(Z_{i, t} Z_{i, t}^{\prime}\right)^{-1}\left(\sum_{t=1}^{T}\left(Z_{i, t} \tilde{y}_{i, t}\right)\right]\right.\right.$

where $Z_{i, t}$ is,

$Z_{i, t}=\left[P P_{i, t}-\overline{P P}_{i}, \Delta P P_{i, t-k_{i}}, \ldots, \Delta P P_{i, t+k_{i}}\right]$

and,

$\tilde{y}_{i, t}=G D P_{i, t}-\overline{G D P}_{i}$ 


\subsubsection{Mean group (MG), pooled mean group (PMG) estimators and causality test}

The short-run coefficients of the panel error correction model were estimated using the PMG method and then the causality relationship between economic growth and petroleum production were examined [34].

There are two methods commonly used for such panels; the first technique namely Mean Group (MG) estimator introduced by Pesaran and Smith [35] and the second alternative estimator that proposed by Pesaran et al. [34] as an intermediate estimator as regards it merges both pooling and averaging.

The first approach estimates separate regression for each country and calculates the coefficients as unweighted means of the estimated coefficients for individual countries. It allows for all coefficients to vary in the long-run. The necessary condition for consistency and validity of this approach is the availability of a sufficiently large time series dimension of data. The cross-country should also be large. In contrast, the main characteristics of PMG are allowing short-run coefficients, including intercepts, speed of the adjustment to the long- run equilibrium values, and the error variances to be heterogeneous country by country. This is while that the longrun slope coefficients are restricted to be homogeneous across countries, Also, one of the advantages of the PMG approach compared with OLS, DOLS, and FMOLS is shortterm dynamic properties which can vary from one crosssection to another in this method, while the long-run coefficients estimated based on the OLS, DOLS and, FMOLS models are assumed to be same in all sections.

If the variables of the model are integrated, the PMG estimator can be used to survey the causality relationship among variables. The panel error correction model (ECM) used is as follows:

$\Delta G D P_{i t}=\alpha_{1 i}+\sum_{k=1}^{m} \beta_{i k} \Delta G D P_{j, t-k}+\sum_{k=1}^{n} \varphi_{i k} \Delta P P_{j, t-k}+\emptyset_{1} E C T_{t-1}+e_{1 t}$

$\Delta P P_{i t}=\alpha_{2 i}+\sum_{k=1}^{m} \theta_{i k} \Delta P P_{j, t-k}+\sum_{k=1}^{n} \vartheta_{i k} \Delta G D P_{j, t-k}+\emptyset_{2} E C T_{t-1}+e_{2 t}$

where error term $e_{t}$ is an independent variable with normal distribution, and $E C T_{t-1}$ is the error correction term resulted from the long-run relationship. Using the above equations, we assessed both the long-run relationship and the short-term relationship among the variables. In order to study the short-run causality relationship between economic growth and petroleum production, the following hypothesis was considered: $H_{0}: \varphi_{i k}=0 \forall i k$
Table 1 Cross-sectional dependence test results

\begin{tabular}{ll}
\hline Test & Statistic \\
\hline Breusch-Pagan LM & $519.46^{* * *}$ \\
& $(0.0000)$ \\
Pesaran scaled LM & $43.23^{* * *}$ \\
& $(0.0000)$ \\
Pesaran CD & $3.793^{* * *}$ \\
& $(0.0001)$ \\
\hline
\end{tabular}

***, ** and * represent significant level at $1 \%, 5 \%$ and $10 \%$, respectively

ns indicates insignificant level

Table 2 The results of panel unit root test

\begin{tabular}{llllll}
\hline Variables & \multicolumn{2}{l}{ IPS w-stat } & & \multicolumn{2}{l}{ Breitung t-stat } \\
\cline { 2 - 3 } \cline { 5 - 6 } \cline { 5 - 6 } & Level & First difference & & Level & First difference \\
\hline LOP & -1.14 & $-2.85^{* * *}$ & & 1.84 & $-2.01^{* *}$ \\
& $(0.13)$ & $(0.002)$ & & $(0.96)$ & $(0.03)$ \\
LGDP & -1.26 & $-3.23^{* * *}$ & & 0.73 & $-2.53^{* * *}$ \\
& $(0.11)$ & $(0.001)$ & & $(0.76)$ & $(0.005)$ \\
\hline
\end{tabular}

Where $\phi_{\mathrm{ik}}$ denotes the short-run causality relationship from petroleum production to economic growth, and $\vartheta_{\text {ik }}$ is the reverse direction of short-run causality. As a result, the hypothesis can be rewritten as follows:

$H_{0}: \vartheta_{i k}=0 \quad \forall i k$

When $\varphi_{i k}$ and $\vartheta_{i k}$ are statistically significant, there would be a short-run causality between variables.

Finally, the existence of a long-run relationship between the variables in above equation was tested by significant levels of $\emptyset$ which are associated with the ECT in the model.

\section{The empirical and estimation results}

\subsection{Cross-sectional dependency tests results}

We commence our empirical analysis with the testing for cross-sectional dependency between OPEC countries. For this purpose we conducted three cross-sectional dependency tests Breusch-Pagan LM; Pesaran scaled LM and Pesaran CD. According to the results given in Table 1, the null hypothesis of the absence of cross-section dependency was rejected at a $1 \%$ level of significance. Therefore, one can conclude that a shock occurring in one OPEC member would impact other OPEC members. 
Table 3 Pedroni co-integration test results

\begin{tabular}{lcl}
\hline & Statistic & Weighted statistic \\
\hline Within dimension & & \\
Panel v-statistic & 0.44 & -0.16 \\
Panel p-statistic & $-3.26^{* * *}$ & $-3.41^{* * *}$ \\
Panel PP-statistic & $-5.08^{* * *}$ & $-4.97^{* * *}$ \\
Panel ADF-statistic & $-5.09^{* * *}$ & $-4.81^{* * *}$ \\
Between dimension & & \\
Group p-statistic & $-1.94^{* *}$ & \\
Group PP-statistic & $5.79^{* * *}$ & \\
Group ADF-statistic & $-4.6^{* * *}$ & \\
Kao residual co-integration test & & \\
ADF & $-2.88^{* * *}$ & \\
\hline
\end{tabular}

Table 4 Panel FMOLS and DOLS estimates

\begin{tabular}{lll}
\hline Method & Panel FMOLS & Panel DOLS \\
\hline LPP & $0.64^{* *}$ & $0.76^{* *}$ \\
& $(6.87)$ & $(5.4)$ \\
R-square & 0.98 & 0.97 \\
\hline
\end{tabular}

\subsection{Panel unit root tests results}

Table 2 shows the outcome series of two-panel unit root tests determined for the OPEC countries. The null hypothesis of unit roots for the panel data for the natural logarithm of economic growth and petroleum production was not rejected. When these series were first differenced, this hypothesis was, however, rejected. The results imply that the variables in the level were non-stationary and were stationary in first-differences. According to the results of the unit root test and the non-stationary evidence of variables at the level, we examined the panel co-integration test between the variables.

\subsection{The results of panel co-integration tests}

In this section with considering the results of panel unit root tests and ensuring that all the variables used in this study were integrated in the first order, we assessed the existence of a long-run relationship between them. In order to investigate the panel co-integration relationship between variables, two tests of the Paderoni and Kau panel co-integration were employed. Table 3 represents the results of Pedroni's and Kau co-integration tests between economic growth and petroleum production series. We also used four within-group and three between-group tests to investigate whether the panel data were co-integrated. Except for the v-statistic test, all the within-group tests, between-group tests, and Kau test showed that the null hypothesis of absence of cointegration was rejected at $1 \%$ and $5 \%$ significant level. The variables were thus co-integrated for the panel of OPEC countries. It can be concluded that the studied variables tended to have a long-term relationship.

\subsection{The results of FMOLS and DOLS estimates}

In the current investigation, we applied several panel cointegrating estimators such as fully modified OLS, the dynamic OLS, and the pooled mean group. The results of FMOLS and DOLS models are given in Table 4, the variable used in natural logarithms, the outputs show the elasticities. The petroleum production coefficients estimated by FMOLS and DOLS were 0.54 and 0.66 for the pool of all OPEC members, respectively. These coefficients were statistically significant at $1 \%$ significances level. According to these estimates, the petroleum production had positive effects on the economic growth indicating the positive influences of PP on GDP growth. FMOLS results demonstrated that $1 \%$ increase in the petroleum production enhances the GDP by $0.64 \%$. Also, the coefficient of DOLS indicated that $1 \%$ PP rise causes a $0.76 \%$ growth of GDP which is consistent with those obtained by the FMOLS model.

\subsubsection{The results of FMOLS estimation (country wise)}

Table 5 shows the FMOLS estimation method results for individual countries of OPEC. Except Ecuador and Venezuela $\mathrm{RB}$, the petroleum production positively significantly affected individual economic growth in the OPEC countries. Moreover, petroleum production seems to have the greatest impact on economic growth in Kuwait and Emirate.

Table 5 The FMOLS Estimation (country-wise) results

\begin{tabular}{llllllllllll}
\hline Country & Algeria & Angola & Ecuador & Iran & Iraq & Kuwait & Nigeria & Qatar & Saudi Arab & Emirate & Venezuela RB \\
\hline LOP & $0.33^{* * *}$ & $0.59^{* * *}$ & $0.13^{\text {ns }}$ & $0.63^{* * *}$ & $0.47^{* * *}$ & $1.83^{* * *}$ & $0.85^{* *}$ & $0.40^{* * *}$ & $0.42^{* * *}$ & $2.13^{* * *}$ & $0.34^{\text {ns }}$ \\
& $(0.04)$ & $(0.11)$ & $(0.09)$ & $(0.16)$ & $(0.13)$ & $(0.51)$ & $(0.45)$ & $(0.07)$ & $(0.1)$ & $(0.7)$ & $(0.71)$ \\
Constant & 5.72 & 3.6 & 7.4 & 3.22 & 4.6 & -3.4 & 0.3 & 8.3 & 5.9 & -5.5 & 6.6 \\
@trend & $0.01^{* * *}$ & $0.012^{\text {ns }}$ & $0.02^{* * *}$ & $0.02^{* * *}$ & $0.004^{\text {ns }}$ & $-0.05^{* * *}$ & $0.04^{* * *}$ & $-0.02^{* * *}$ & $0.007^{* * *}$ & $-0.1^{* * *}$ & $0.012^{\text {ns }}$ \\
& $(0.001)$ & $(0.008)$ & $(0.002)$ & $(0.003)$ & $(0.008)$ & $(0.01)$ & $(0.005)$ & $(0.004)$ & $(0.002)$ & $(0.02)$ & $(0.01)$ \\
\hline
\end{tabular}


Table 6 Hausman test for MG and PMG estimator

\begin{tabular}{lllll}
\hline \multicolumn{2}{l}{ Coefficients } & & & \\
\hline & (b) & (B) & (b-B) & Sqrt (diag (V_b-V_B) \\
& MG & PMG & Difference & S.E \\
\hline LOP & -0.2606 & 0.8643 & -1.125 & 2.2048 \\
\hline
\end{tabular}

Prob $>$ chi $2=0.6099$

Table 7 Results of error correction model (ECM) using pooled mean group (PMG) estimator

\begin{tabular}{|c|c|c|c|}
\hline \multicolumn{2}{|c|}{ Dependent variable: D.LGDP } & \multicolumn{2}{|c|}{ Dependent variable: D.LPP } \\
\hline $\begin{array}{l}\text { Independent } \\
\text { variables }\end{array}$ & Coefficients & $\begin{array}{l}\text { Independent } \\
\text { variables }\end{array}$ & Coefficients \\
\hline \multicolumn{4}{|l|}{ Long-run } \\
\hline LPP & $\begin{array}{l}0.8643 * * * \\
(0.0693)\end{array}$ & LGDP & $\begin{array}{l}0.1093^{n s} \\
(0.1279)\end{array}$ \\
\hline \multicolumn{4}{|l|}{ Short-run } \\
\hline $\mathrm{D}(\mathrm{LPP})$ & $\begin{array}{l}0.3972^{* * *} \\
(0.1142)\end{array}$ & $\mathrm{D}(\mathrm{LGDP})$ & $\begin{array}{l}0.8340^{* * * *} \\
(0.1394)\end{array}$ \\
\hline $\mathrm{C}$ & 0.2027 & $\mathrm{C}$ & 0.9896 \\
\hline ECT & $\begin{array}{l}-0.1161^{* * *} \\
(0.0528)\end{array}$ & ECT & $\begin{array}{l}-0.1433^{* * * *} \\
(0.0569)\end{array}$ \\
\hline
\end{tabular}

\subsection{The results of PMG and MG estimators}

\subsubsection{Hausman tet}

In this section, we estimated the PMG and MG equation. The validity of the long-run homogeneity restriction cross countries and the efficiency of the PMG estimator over the MG estimator were then examined by Hausman test. In this test, the null hypothesis is that the difference between PMG and MG is not significant. If the null hypothesis doesn't be rejected, the PMG estimator is efficient. As shown in Table 6, the Hausman test accepted the null hypothesis implying that PMG was more efficient estimator than MG.

\subsubsection{PMG estimator and ECM results}

Table 7 shows the results obtained for both the long-run and short-run relationship and standard deviation in parenthesis between LPP and LGDP by using the PMG estimator. The optimal lag in this model was equal to 1 selected based on the Schwarz-Bayesian criterion. The estimation of the error correction model (ECM) made it possible to investigate the causality relationships between variables in the short and long run separately. As shown in Table 7, there was a unidirectional causality in long-run. When the first difference of LGDP was the dependent variable, the longrun coefficient of LPP variable estimated to be 0.86 (significant at level of 1\%). Putting it differently, the long-run petroleum production influenced the economic growth. On the contrary, there was no causality of economic growth due to long-run petroleum production when the first difference of LPP was considered as the dependent variable. Further, there was a causality relation from the petroleum production variable to the economic growth variable (Table 7). In other words, short-run petroleum production affected the economic growth. Given the amount of error correction term (ECT) coefficients (Table 7), approximately $11 \%$ of economic growth distortion was adjusted from long-term equilibrium. When the first difference of LPP was considered as the dependent variable, the coefficient of error correction term in this mode equaled -0.14 and was significant at $1 \%$ significance level. There was a causal relationship between the economic growth variable and the petroleum production variable in the short-run as the first difference of economic growth variable was found to be significant. In other words, in short-term economic growth impacted the petroleum production. The value of error correction term coefficient demonstrates that $14 \%$ of the petroleum production deviation from long-term equilibrium was adjusted during each period.

\section{Conclusions}

In this study, the relationship between economic growth and petroleum production for Organization of the Petroleum Exporting Countries (OPEC) were studied by applying panel co-integration methods. In order to examine the existence of this relationship, two panel co-integration tests were used. Furthermore, DOLS and FMOLS panel cointegration techniques were employed to estimate the long-run coefficients. In addition, the short-run coefficient and causality relationship were estimated using the PMG method. The results showed that gross domestic production (GDP) and petroleum production (PP) were non-stationary and co-integrated series. Petroleum production had positive effects on economic growth for the pool of OPEC members estimated PP coefficients of 0.76 (DOLS), 0.64 (FMOLS) and 0.86 (PMG). For all OPEC countries except Ecuador and Venezuela RB, PP positively significantly influenced GDP growth supporting the growth hypothesis for these countries. Therefore, adopting expansionary policies in petroleum sector seems to benefit the country. Ecuador and Venezuela RB must follow energy conversation policies towards petroleum utilization. The largest contribution of PP to the GDP growth was found for Kuwait and Emirate with coefficients of $1.83,2.13$, respectively. One can thus conclude that oil policies and investments in the oil sector should be different in these two countries. PP had also long-run and short-run positive effects on economic growth in these countries. However, the economic growth 
only had short-run causality with PP. This causality was, therefore, a unilateral causality from PP to GDP. Overall, petroleum production is one of the most important affecting factors for economic growth in the OPEC countries.

\section{Compliance with ethical standards}

Conflict of interest The authors declare that they have no conflict of interest.

\section{References}

1. Hall C, Tharakan P, Hallock J, Cleveland C, Jefferson M (2003) Hydrocarbons and the evolution of human culture. Nature 426(6964):318-322

2. Stern DI (1999) Is energy cost an accurate indicator of natural resource quality? Ecol Econ 31(3):381-394. https://doi. org/10.1016/S0921-8009(99)00060-9

3. Bildirici ME, Bakirtas T (2014) The relationship among oil, natural gas and coal consumption and economic growth in BRICTS (Brazil, Russian, India, China, Turkey and South Africa) countries. Energy 65:134-144. https://doi.org/10.1016/j.energ y.2013.12.006

4. Organization of the Petroleum Exporting Countries (2016) https ://www.opec.org/opec_web/en/. Accessed 8 June 2018

5. Solarin SA, Ozturk I (2016) The relationship between natural gas consumption and economic growth in OPEC members. Renew Sustain Energy Rev 58:1348-1356. https://doi.org/10.1016/j. rser.2015.12.278

6. Anon (2017) U.S. Energy Information Administration (EIA). US Energy Information Administration. https://www.eia.gov/. Accessed 8 June 2018

7. The World Bank (2018) World Bank Group_International Development, Poverty, \& Sustainability. https://www.worldbank.org/. Accessed 8 June 2018

8. Toman M (2003) The roles of the environment and natural resources in economic growth analysis. Resources for the future. Discussion Paper. May, pp 1-71

9. Stern DI (1993) Energy and economic growth in the USA: a multivariate approach. Energy Econ 15(2):137-150. https://doi. org/10.1016/0140-9883(93)90033-N

10. Auty R (2003) Natural resources and 'gradual' reform in Uzbekistan and Turkmenistan. Nat Resour Forum 27(4):255-266. https ://doi.org/10.1111/j.0165-0203.2003.00060.x

11. Gelb A, Jefferson G, Singh I (1993) Can communist economies transform incrementally? The experience of China. NBER Macroecon Annu 8:87-133

12. Neary JP, van Wijnbergen S (1985) Natural resources and the macroeconomy: a theoretical framework. School of Economics, University College Dublin

13. Sachs JD, Warner AM (1995) Natural resource abundance and economic growth. National Bureau of Economic Research

14. Ahrend R (2005) Speed of reform, initial conditions or political orientation? Explaining Russian regions' economic performance. Post-Communist Econ 17(3):289-317. https://doi. org/10.1080/14631370500204198

15. Barbier EB (2007) Natural resources and economic development. Cambridge University Press, Cambridge

16. Bildirici ME, Kayıkçı $F$ (2013) Effects of oil production on economic growth in Eurasian countries: panel ARDL approach. Energy 49:156-161. https://doi.org/10.1016/j.energy.2012.10.047
17. Reynolds DB, Kolodziej M (2008) Former Soviet Union oil production and GDP decline: Granger causality and the multicycle Hubbert curve. Energy Econ 30(2):271-289. https://doi. org/10.1016/j.eneco.2006.05.021

18. Bashiri Behmiri N, Pires Manso JR (2012) Crude oil conservation policy hypothesis in OECD (organisation for economic cooperation and development) countries: a multivariate panel Granger causality test. Energy 43(1):253-260. https://doi.org/10.1016/j. energy.2012.04.032

19. Behmiri NB, Pires Manso JR (2014) The linkage between crude oil consumption and economic growth in Latin America: the panel framework investigations for multiple regions. Energy 72:233-241. https://doi.org/10.1016/j.energy.2014.05.028

20. Breusch TS, Pagan AR (1980) The Lagrange multiplier test and its applications to model specification in econometrics. Rev Econ Stud 47(1):239-253. https://doi.org/10.2307/2297111

21. Pesaran H (2004) General diagnostic tests for cross section dependence in panels. CESifo Working Papers 69

22. Ramirez MD (2010) Are foreign and public capital productive in the Mexican case? A panel unit root and panel cointegration analysis. East Econ J 36(1):70-87

23. Engle RF, Granger CWJ (1987) Co-integration and error correction: representation, estimation, and testing. Econometrica 55(2):251-276. https://doi.org/10.2307/1913236

24. Pesaran MH (2007) A simple panel unit root test in the presence of cross-section dependence. J Appl Econom 22(2):265-312. https://doi.org/10.1002/jae.951

25. Kao C (1999) Spurious regression and residual-based tests for cointegration in panel data. J Econom 90(1):1-44. https://doi. org/10.1016/S0304-4076(98)00023-2

26. Pedroni $P$ (1999) Critical values for cointegration tests in heterogeneous panels with multiple regressors. Oxford Bull Econ Stat 61(S1):653-670. https://doi.org/10.1111/1468-0084.0610s1653

27. Im KS, Pesaran MH, Shin $Y$ (2003) Testing for unit roots in heterogeneous panels. J Econom 115(1):53-74. https://doi. org/10.1016/S0304-4076(03)00092-7

28. Ouedraogo NS (2013) Energy consumption and economic growth: evidence from the economic community of West African States (ECOWAS). Energy Econ 36:637-647. https://doi. org/10.1016/j.eneco.2012.11.011

29. Pedroni $P$ (2001) Purchasing power parity tests in cointegrated panels. Rev Econ Stat 83(4):727-731

30. Ozturk I (2010) A literature survey on energy-growth nexus. Energy Policy 38(1):340-349. https://doi.org/10.1016/j.enpol .2009 .09 .024

31. Peter CBP, Hansen BE (1990) Statistical inference in instrumental variables regression with I(1) processes. Rev Econ Stud 57(1):99125. https://doi.org/10.2307/2297545

32. Kao C, Chiang M-H (1999) On the estimation and inference of a cointegrated regression in panel data. Available at SSRN 1807931

33. Mark NC, Sul D (2003) Cointegration vector estimation by panel DOLS and long-run money demand. Oxford Bull Econ Stat 65(5):655-680. https://doi.org/10.1111/j.1468-0084.2003.00066.x

34. Pesaran MH, Shin Y, Smith RP (1999) Pooled mean group estimation of dynamic heterogeneous panels. J Am Stat Assoc 94(446):621-634. https://doi.org/10.2307/2670182

35. Pesaran MH, Smith R (1995) Estimating long-run relationships from dynamic heterogeneous panels. J Econom 68(1):79-113. https://doi.org/10.1016/0304-4076(94)01644-F

Publisher's Note Springer Nature remains neutral with regard to jurisdictional claims in published maps and institutional affiliations. 